\title{
The effects of economic integration on regional growth, an evolutionary model
}

\author{
by \\ M.C.J. Caniëls (TUE) and B. Verspagen (ECIS and MERIT)
}

October 1999

\begin{abstract}
This paper will present a multi-region-multi-country model in which inter-regional knowledge spillovers determine the growth of regions. Key parameters in the model are the learning capability of a region, and the exogenous rate of knowledge generation (R\&D). The intensity of spillovers depends on geographical distance between regions. The model is investigated by means of simulation techniques. What results is a core-periphery situation, the exact form of which depends on the assumed spatial structure. One surprising result of the analysis is that larger technological differences between regions may lead to smaller disparity in terms of the long-run spatial distribution of GDP per capita.

The impact of economic integration is investigated by comparing two different aspects of the model. First, examining a fixed exchange rate system versus a system of flexible exchange rates results in conditions (constellations of parameters) under which fixed exchange rates (compared to flexible exchange rates) generate less disparity across regions. However, depending on the parameter values, fixed exchange rates may also generate more disparity, leading to the conclusion that the effect of monetary integration is ambiguous.

Second, the impact of barriers to knowledge spillovers is analysed by assuming that cross border knowledge flows are hampered compared to inter-country flows. This results in the observation that reduced cross border flows have a large impact when regions are initially unequal with respect to their exogenous rate of knowledge generation or their learning capability. In these cases, the resulting trends in overall disparity are quite different from the trends established in a situation of no barriers to knowledge spillovers.
\end{abstract}




\section{Introduction}

The issue of convergence of GDP per capita is the topic of a large and growing literature in economics (e.g., Barro and Sala-i-Martin, 1995, Fagerberg, 1994). The general conclusion from this literature is that convergence, as opposed to divergence, is a special outcome that may prevail between a set of countries that is relatively homogenous in terms of variables such as knowledge generation (R\&D), infrastructure, educational systems, etc. This idea is implicit in the notion of 'conditional convergence' that arises from new growth models in the neoclassical tradition (e.g., Barro and Sala-i-Martin, 1995), as well as in the so-called technology gap theory (e.g., Fagerberg, 1994).

Economic integration, for example in the form that has been implemented in the European Union, may well help to achieve homogeneity between countries with regard to the above mentioned structural characteristics, and thus help to achieve convergence (e.g., Ben-David, 1994). However, the empirical evidence on convergence of GDP per capita among European regions seems to point out that such convergence is not, or in the best case at very low speed, taking place at the regional level in the Union at large since the start of the 1980s (Fagerberg, Verspagen and Caniëls, 1997).

This paper suggests that the impact of spatial proximity on the diffusion of technological knowledge may be responsible for this paradoxical situation. There is a large literature in economic geography that underlines the importance of proximity for knowledge spillovers. The concept of interest in this literature (for an overview see Baptista, 1998) is the existence of agglomeration economies and its effects on growth. Agglomeration economics involve the positive effects on a firm or a region generated by a spatial concentration of economic activity. Agglomeration economies are induced, among others, by a large opportunity for communication of ideas and experience, which is enhanced by spatial proximity. In this paper we focus on knowledge spillovers as the prime form of agglomeration economies. Several studies (e.g., Acs, Audretsch and Feldman, 1992, Jaffe, Trajtenberg and Henderson, 1993) have confirmed such a positive relation between geographic proximity and knowledge spillovers.

Theoretical reasons for the localized nature of knowledge spillovers are as follows. Technological knowledge is often informal, tacit and uncodified in its nature (e.g., Pavitt, 1987). This implies that there are differences between knowledge and information, where the former concept is more far-reaching than the latter. Audretsch and Feldman (1996) argue that although the cost of transmitting information may be invariant to distance, presumably the cost of transmitting knowledge rises with distance. Possibilities for learning-by-doing and learning-by-using, important for the transmission of knowledge, to a large extent come from direct contacts with competitors, customers, suppliers and providers of services (Von Hippel, 1988, 1994) and are therefore highly dependent on proximity.

Uncertainty is another characteristic of the innovative process. Interaction between innovators, e.g. in regional networks, helps to reduce this uncertainty. This kind of interaction is highly dependent on geographical proximity. In this respect, Freeman (1991) points out that networks frequently tend to be localised. Another reason why proximity has an effect on the innovative process lies in the fact that innovation relies heavily upon sources of basic 
scientific knowledge. Jaffe (1989) and Acs, Audretsch and Feldman (1992) have empirically shown that knowledge spillovers from university research to private firms are facilitated by geographic proximity. Furthermore, innovative activity is cumulative, meaning that new innovations build upon scientific knowledge generated by previous innovations. Breschi (1995) and Malerba and Orsenigo (1995) point out that the accumulation of innovative activity in a geographic area facilitates the generation of new innovations in this area.

In this paper we incorporate spatial proximity into a technology gap growth model developed earlier by Verspagen (1991). The resulting model, which is discussed in greater detail in Caniëls (1999) is one in which a multitude of geographic units (which will be called regions) interact with each other in terms of knowledge diffusion. These regions may differ with respect to their R\&D efforts and their social capability to assimilate knowledge from other regions. Ceteris paribus, knowledge from regions close by diffuses more easily than knowledge from regions far away.

Barriers to trade and barriers to knowledge spillovers can have an important influence on the distribution of growth across regions. First, trade can have an influence on growth, by enhancing specialisation and thus enabling increasing returns to scale. Various trade-growth models explore this relation (Grossman and Helpman, 1990). Second, international specialisation may have an impact on the amount of spillovers that take place within a country relative to the amount between countries. Thus, barriers to trade and to knowledge spillovers may well have an influence on the distribution of gaps throughout all regions.

To be able to study these influences, the situation under barriers to trade and knowledge spillovers is compared to a situation in which these barriers are released. In other words, comparing a situation before and after these two forms of economic integration will make it possible to explore the effects of trade barriers on the distribution of growth.

It is difficult to make a clear-cut distinction between barriers to trade and barriers to knowledge spillovers. International barriers to trade come in various formats. Exchange rate volatility, quota's, tariffs and a political unstable situation all form barriers to international trade. Under the (Millian) assumption that trade in goods is accompanied by diffusion of knowledge (every product contains information about for instance its construction that can be deduced by reverse engineering) a barrier to cross country trade can limit the knowledge spillovers in these directions. However, trade is one (indirect) way in which knowledge is diffused.

The aim of this paper is to explore the effects of trade barriers and barriers to knowledge spillovers on regional disparities in growth. The model developed in this paper will take into account increasing returns, through the Verdoorn effect. Specialisation will not be endeepened as a source of disparity across regions, since only one sector will be introduced.

The rest of this paper is organised as follows. In Section 2, the part of the model that describes technological spillovers across regions is presented. Section 3 extends the model to a multi-country setup. Section 4 examines the effect of trade barriers on the model by comparing a fixed exchange rate system to a system of flexible exchange rates by means of simulation techniques. The effect of barriers to knowledge spillovers are analysed in Section 5. Finally, Section 6 summarises the main conclusions from this paper. 


\section{Description of the spillover system}

For simplicity, we disregard any sources of output growth other than the growth of technological knowledge. Specifically, it is assumed that output growth is a linear function of the growth of the knowledge stock:

$$
\frac{\dot{Q}_{i}}{Q_{i}}=\beta \frac{\dot{K}_{i}}{K_{i}}
$$

in which $Q_{i}$ denotes the level of output of region $i$ and $K_{i}$ points to the level of the knowledge stock of region $i$. $\beta$ is a parameter, indicating the proportion of the knowledge stock growth that results in output growth. Dots above variables denote time derivatives.

New knowledge is assumed to stem from three sources: learning-by-doing (modelled as a Verdoorn effect ${ }^{1}$ ), spillovers received from surrounding (not necessarily contingent) regions $\left(S_{i}\right)$, and an exogenous rate of growth $\left(\rho_{i}\right)$, which can be thought of as reflecting the impact of exogenous $R \& D$ activities in the region. This yields the following equation:

$$
\frac{\dot{K}_{i}}{K_{i}}=\alpha\left(\lambda \frac{\dot{Q}_{i}}{Q_{i}}+S_{i}+\rho_{i}\right),
$$

in which $\alpha$ and $\lambda$ are parameters. $\alpha$ points out the extent to which the knowledge stock growth is influenced by the above factors, and $\lambda$ reflects the intensity of the Verdoorn effect.

For the explanation of the spillover term $S$, it is convenient to first consider two regions, later on this framework will be extended, and a multi-region model will be constructed. In the two-region setting, it is assumed that there is one technologically advanced region and one backward region. Spillovers depend on the size of the knowledge gap, as well as three different parameters reflecting distinct effects related to the realisation of potential spillovers. We use the following equation to model spillovers:

$$
\begin{gathered}
S_{i}=\frac{\delta_{i}}{\gamma_{i j}} e^{-\left(\frac{1}{\delta_{i}} G_{i j}-\mu_{i}\right)^{2}}, \\
G_{i j}=\ln \frac{K_{i}}{K_{j}},
\end{gathered}
$$

in which $S_{i}$ denotes the spillovers generated by region $j$ and received by region $i^{2} . G_{i j}$ denotes the technology gap of region $i$ towards region $j$, and is defined as the log of the ratio of the

\footnotetext{
${ }^{1}$ The Verdoorn-Kaldor law states that a positive relation exists between the growth of productivity and the growth of output.

${ }^{2}$ Note that the lower the initial stock of knowledge a region is endowed with, the more spillovers it will receive. This is similar to the concept of $\beta$-convergence (Barro, 1984; Baumol, 1986; De Long, 1988; Barro and Sala-iMartin, 1991, 1992a, 1992b) in which a backward economy (an economy with a low initial level of GDP per capita) will grow faster than a rich economy and therefore catch up.
} 
knowledge stocks of two regions. The realisation of the potential spillover level depends on the three parameters $\gamma, \delta$ and $\mu$, which we will now discuss in turn.

$\gamma_{\mathrm{ij}}$ is the geographical distance between two regions. If $\gamma_{\mathrm{ij}}$ increases, the spillover is reduced. This assumption stems from the geographical literature. As was discussed in the introduction of this paper, this is based on the assumption that spatial proximity eases spillovers (agglomeration economies), because interaction between the receiver and generator of the spillovers is easier when distance is small. $\mu_{\mathrm{i}}$ and $\delta_{\mathrm{i}}$ are two parameters that are related to the intrinsic learning capability of region $i$. These parameters thus reflect the broad concept of 'social capability' to assimilate spillovers (e.g., Abramovitz, 1994). Regions that have a high social capability to learn (e.g., a highly educated workforce, good infrastructure, an efficient financial system, etc.), can implement the knowledge from other regions more easily. $\mu_{\mathrm{i}}$ and $\delta_{\mathrm{i}}$ reflect different parts of the learning capability that will be explained further by means of graphical analysis.

Figure 1 presents the spillover functions for two regions, assuming all parameters to be equal between the regions. The horizontal axis displays the size of the technology gap. Note that a positive value of $G_{i j}$ by definition implies that region $j$ is the backward region. A first characteristic of our model is that, in contrast with most of the catch-up literature, we allow spillovers to occur in two directions, i.e., from the technological leader to backward region(s),

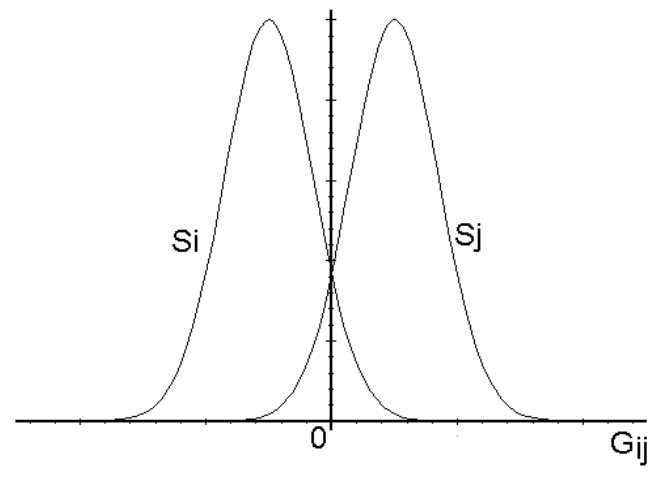

Figure 1: Spillover curve for two regions

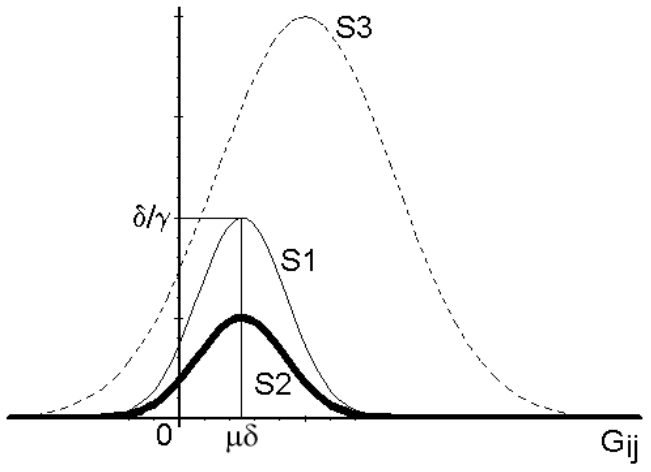

Figure 2: The influence of geographic distance (S2) and the learning capability (S3) on the spillover curve of a region

and vice versa. Figure 1 shows that, for equal parameter values between the regions, the spillover stream from the advanced to the backward region will be larger than the reverse stream ( $S_{i}$ is always below $S_{j}$ to the right of the vertical axis). This reflects the notion that the backward region can learn more than the advanced region. However, spillovers from a backward region to the leader region also take place because it could well be possible that the backward region has (developed) complementary knowledge, knowledge that was not yet in the hands of the leader. So there always is a small flow of knowledge from laggard to leader, although this quantity quickly goes to zero for large gaps.

The net spillover will be equal to zero when the gap between the two regions is zero (i.e., they have equal knowledge stocks). In this situation there are still spillovers, but these are of 
equal size in both directions. This only holds, however, when the parameters $(\rho, \lambda, \mu, \delta)$ are equal between the two regions. In the more general case of unequal parameters between regions, net spillovers may be positive or negative for a gap of value zero.

Figure 2 displays the spillovers received by one region for this two-region model. Note that the top of each spillover curve lies at a technology gap equal to $\mu_{\mathrm{j}} \delta_{\mathrm{j}}$. The maximal spillover corresponding to this is equal to $\delta_{\mathrm{j}} / \gamma_{\mathrm{ij}}$. We take the curve labelled $\mathrm{S} 1$ as the starting point, and we consider what happens to the spillover function under certain conditions. First, an enlargement of the geographical distance between two regions (higher $\gamma$ ) will lead to lower spillovers received by each region, depicted by the thick line S2. Note that an increase in distance shifts the curve down, but leaves the value of the gap for which spillovers are maximal unchanged.

Second, an increase in the learning capability parameter $\delta$ of the lagging region will cause the spillover function to shift up, and the maximum of the curve to shift to the right (dotted line S3). ${ }^{3}$ Thus, with higher $\delta$, the laggard is able to learn more (magnitude of the spillover function) and more easily, or earlier (at a larger technological distance).

As will be explained below, the value of $G$ at which the spillover curve peaks $(\mu \delta)$ is important for the result in terms of convergence or divergence. We therefore want to allow for

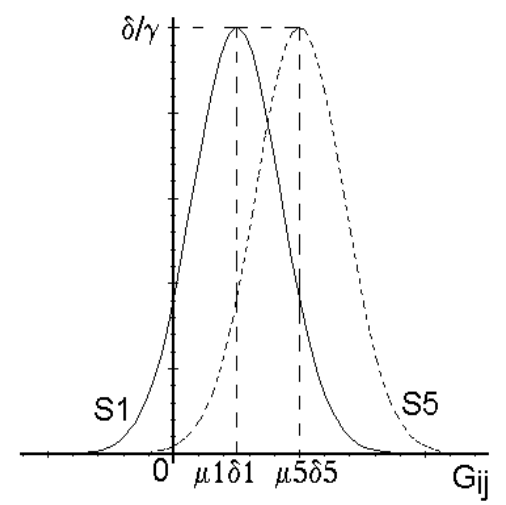

Figure 3: The influence of a change in the catch-up parameter $\mu$ on the spillover curve

the possibility that maximum of the spillover curve shifts left or right, without affecting the value of the maximum itself. Figure 3 shows how the parameter $\mu$ does exactly this.

If $\mu_{\mathrm{j}}$ is increased, all other things being equal, the curve will shift to the right (S5). This has several effects. First, the level of spillovers in the case of equal knowledge stocks across regions $(G=0)$, is smaller. This indicates that for relatively large $\mu$, the model resembles a regular catch-up model, which is characterised by zero spillovers for zero technological distance. Second, because the top of the curve moves to the right, catch-up becomes easier. At a larger technological distance, it is still possible to catch up. How the distinction between catching-up of falling behind works exactly will become clearer after we discuss the net spillover function.

\footnotetext{
${ }^{3}$ To achieve this reaction of the spillover curve, the learning capability had to appear in two places in the spillover function (Equation 3).
} 
Thus, the difference between the parameters $\mu$ and $\delta$ is mainly a technical matter. In practice, they can hardly be disentangled in terms of the variables that make up social capability to assimilate spillovers. We mainly use the parameter $\mu$ to calibrate the model (i.e., to generate a setup that implies a reasonable borderline between catching-up and fallingbehind), while $\delta$ is used more actively in the simulation experiments below as an indicator of the learning capability of a region.

In order to be able to analyse the dynamics of convergence and divergence, we take the time derivative of the technology gap in Equation (4) and substitute equations (1), (2) and (3). For a two-region model this yields:

$$
\dot{G}_{i j}=\frac{d}{d t} \ln \frac{K_{i}}{K_{j}}=\frac{\dot{K}_{i}}{K_{i}}-\frac{\dot{K}_{j}}{K_{j}}=\frac{\alpha}{1-\alpha \beta \lambda}\left(\left(\rho_{i}-\rho_{j}\right)-\left(S_{j}-S_{i}\right)\right), \text { with } 0<\alpha \beta \lambda<1,
$$

in which $\alpha, \beta$ and $\lambda$ are assumed to have the same value in each region. This expression can be analysed using Figure 4.

We will restrict ourselves to describing only one case, namely the one in which region $i$ is the leader, i.e., where the initial gap is positive. We also assume that leadership implies larger R\&D efforts, such that $\rho_{\mathrm{i}}>\rho_{\mathrm{j}} .{ }^{4}$ In Figure $4, S_{\mathrm{j}}-S_{\mathrm{i}}$ represents the difference in received

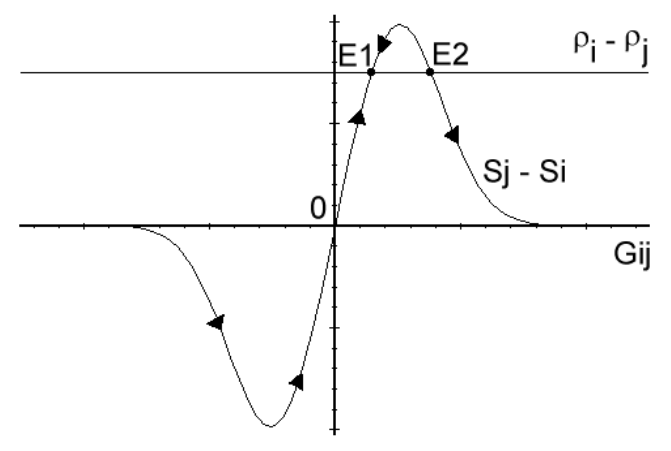

Figure 4: The dynamics of the model

spillovers between the two regions. The lagging region receives positive net spillovers, as discussed above. Note that we have again assumed $\delta_{\mathrm{i}}=\delta_{\mathrm{j}}$ and $\mu_{\mathrm{i}}=\mu_{\mathrm{j}}$. In the more general case where these assumptions do not hold, the net spillover curve will not intersect with the origin, but this does not change the dynamics in a major way. The horizontal line $\rho_{\mathrm{i}}-\rho_{\mathrm{j}}$ displays the difference in the exogenous rate of growth of the knowledge stock between the two regions.

It is straightforward from equation (5) that when the curve in Figure 4 intersects with the horizontal line $\rho_{\mathrm{i}}-\rho_{\mathrm{j}}$, the time derivative of the technology gap is equal to zero. In other words, the intersection points correspond to equilibrium points. The (leftmost) intersection

\footnotetext{
${ }^{4}$ This assumption is not essential. Obviously, the case where region $j$ is the leader is the mirror-image of the case we discuss.
} 
point at which the S-curve has a positive slope is stable, whereas the other intersection point is unstable. Thus, what happens to the knowledge gap in the long run depends on where the process starts. Starting points to the left of E2 will yield convergence to a stable technology gap (corresponding to E1). Starting values to the right of E2 will yield falling behind, with an ever growing knowledge gap. ${ }^{5}$

Now consider what happens with changing parameter values. We will first consider a variation in the difference in the exogenous rate of growth of the knowledge stock between the two regions, $\rho_{\mathrm{i}}-\rho_{\mathrm{j}}$. If the difference is enlarged in favour of the leader, the $\rho_{\mathrm{i}}-\rho_{\mathrm{j}}$ line in Figure 4 moves upward, meaning that the range of technology gaps at which catch-up occurs becomes smaller. Eventually, when the $\rho_{\mathrm{i}}-\rho_{\mathrm{j}}$ line shifts to a position above the net spillover curve, there will be no opportunity at all for catch-up. If, on the other hand, the exogenous rate of growth of the knowledge stock in the backward region is increased (e.g. by expanding research efforts) up to a level comparable with the advanced region, i.e., the $\rho_{i}-\rho_{j}$ line ultimately coincides with the horizontal axis, and the (stable) equilibrium gap is zero, implying complete converge in the long run.

Next, we consider the impact of the geographical distance between the two regions. A

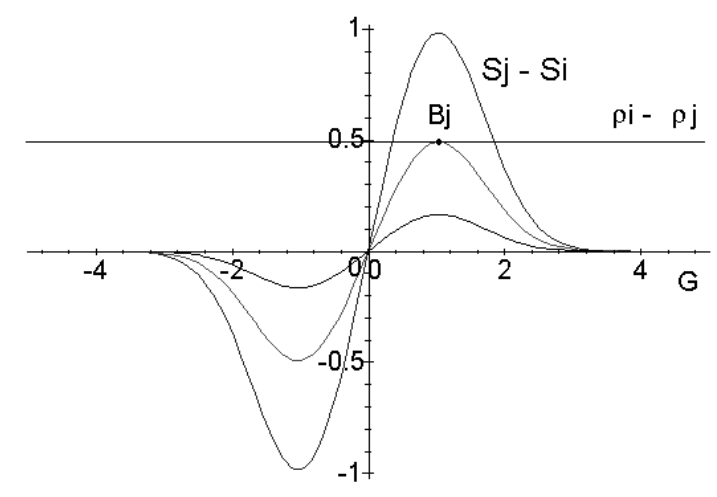

Figure 5: The impact of geographical distance on the net spillover curve

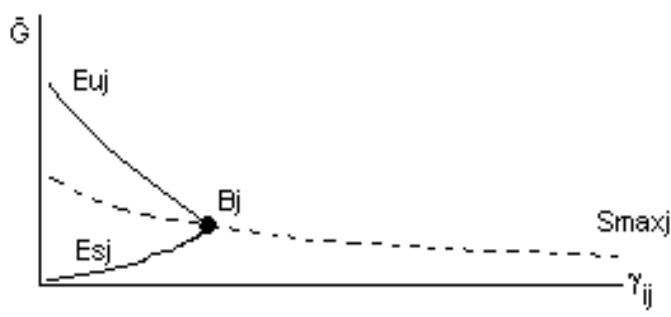

Figure 6: Bifurcation with respect to geographical distance

decrease in the geographical distance has the effect that the spillover curves $S_{i}$ and $S_{j}$ increase proportionally to the decrease in geographical distance (explained by Figure 2) and the maximum of the $S_{\mathrm{j}}-S_{\mathrm{i}}$ curve in Figure 5 moves upwards ${ }^{6}$. Figure 6 displays the bifurcation diagram for this case. ${ }^{7}$ The horizontal axis of the bifurcation diagram shows the values of the geographical distance parameter $\gamma_{\mathrm{ij}}$. The vertical axis shows the equilibrium values of the technology gap. The line $\mathrm{E}_{\mathrm{sj}}$ shows the stable equilibrium, while the line $\mathrm{E}_{\mathrm{uj}}$ points to the unstable equilibrium. The line $S_{\operatorname{maxj}}$ represents the top of the net spillover curve in Figure 5.

\footnotetext{
${ }^{5}$ Verspagen (1991) estimates a simpler version of this model for a large sample of countries over the post-war period, and finds that falling behind is a frequent phenomenon.

${ }^{6}$ The maximum also moves a little bit away from the y-axis, but this is a very small effect.

${ }^{7}$ Note that the figure should show a discontinuous graph (in the model a geographical distance is either 1 or 2 , not 1.5), however, for visual reasons the individual points are connected.
} 
This figure shows that for high values of $\gamma_{i j}$ no equilibrium value of the technology gap exists. In terms of Figure 5, this occurs when there are no intersection points between the curves. For a threshold value of $\gamma_{\mathrm{ij}}$, one equilibrium appears. This occurs when the two curves in Figure 5 are tangent. For values of $\gamma_{\mathrm{ij}}$ smaller than the threshold level, two equilibria exist, as described by the curves in the bifurcation diagram.

A similar bifurcation analysis can be performed for the parameter $\delta$. The effect of an increase in the learning capability of the backward region $j\left(\delta_{\mathrm{j}}\right)$ on the $\mathrm{S}_{\mathrm{j}}-\mathrm{S}_{\mathrm{i}}$ curve is displayed in Figure 7. Note that $\delta_{\mathrm{j}}$ is the only parameter that has changed, $\delta_{\mathrm{i}}$ is kept constant. It can clearly be seen that on the right hand side of the figure the top of the curve has moved to the upper right of the figure and the curve does not intersect with the origin anymore. What has happened on the left-hand side is a bit more difficult to see. The minimum point has moved

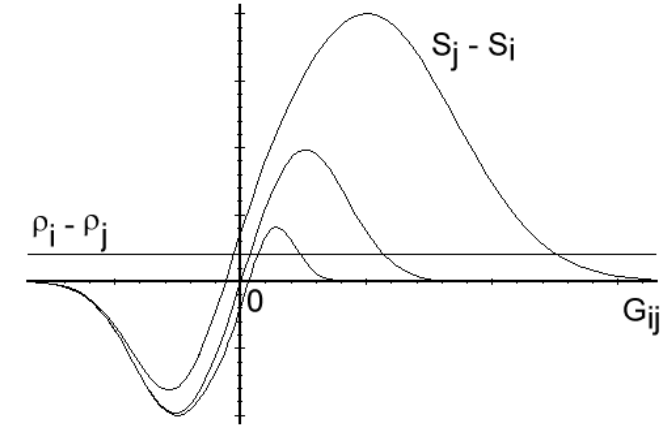

Figure 7: The impact of the learning capability on the net spillover curve

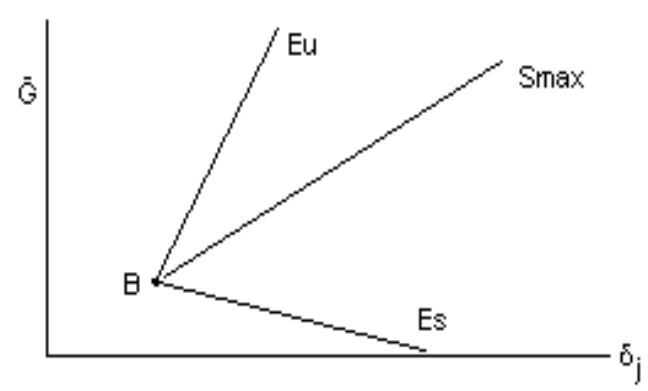

Figure 8: Bifurcation with respect to the learning capability

upwards so that it is closer to the horizontal axis. Also, there is a small movement of the minimum point away from the y-axis. The bifurcation diagram now looks as displayed in Figure 8.

Note that the $E_{s}$ line for the stable equilibrium can even go below the $x$-axis if the difference in exogenous growth rates of the knowledge stock is small enough, which illustrates an interesting special case of the model. This situation indicates a take-over in leadership by the (initially) lagging region. In terms of Figure 7, this occurs when the horizontal line $\left(\rho_{\mathrm{i}}-\rho_{\mathrm{j}}\right)$ intersects with the $S_{\mathrm{j}}-S_{\mathrm{i}}$ curve left from the y-axis, where the gap is smaller than zero, indicating that region $j$ is the leader region. The combination of a large learning capability in the lagging region together with a small difference in the exogenous rate of growth between laggard and leader gives rise to a take over of the lead position by the backward region. Note that it is primarily learning capability that drives this process of takeover.

We omit the bifurcation analysis for the $\mu$ parameter, which is relatively straightforward, and jump to extend the model to a multi-regional case. Suppose we have a world with $k$ regions, so that each region can be characterised by $k-1$ technology gaps (we omit the trivial case of $G_{i i}$ ). Spillovers are received from each of the other regions, so that the $S$ terms in 
equation (2) now become sums of spillovers over $k$ - 1 regions. This gives rise to the following modified form of equation (5):

$$
\begin{gathered}
\dot{G}_{i j}=\frac{d}{d t} \ln \frac{K_{i}}{K_{j}}=\frac{\dot{K}_{i}}{K_{i}}-\frac{\dot{K}_{j}}{K_{j}}=\frac{\alpha}{1-\alpha \beta \lambda}\left(\left(\rho_{i}-\rho_{j}\right)+\left(\Sigma_{n} S_{i n}-\Sigma_{n} S_{j n}\right)-\left(S_{j}-S_{i}\right)\right), \\
\text { with } 0<\alpha \beta \lambda<1 \text { and } n \neq i, j,
\end{gathered}
$$

in which $\Sigma_{n} S_{i n}$ and $\Sigma_{n} S_{j n}$ denote the spillovers received by region $i$ and $j$ respectively from all regions $n$ for which $n \neq i, j$ (this term is thus invariant to $G_{i j}$ ). Note that equation (5') specifies the (growth of the) gap between the two regions $i$ and $j$ only. There are $k$ regions in total, thus every region $i$ has $k-1$ of these equations.

Equation (5'), under the ceteris paribus assumption with respect to the knowledge stocks in regions other than $i$ and $j$, gives rise to identical figures as Figures 4-8. The only difference is that in the case of equation $\left(5^{\prime}\right),\left(\rho_{i}-\rho_{j}\right)$ and $\left(\Sigma_{n} S_{i n}-\Sigma_{n} S_{j n}\right)$ are lumped together into the horizontal lines that used to be determined by $\left(\rho_{i}-\rho_{j}\right)$ only. A movement of this horizontal line (and therefore in the horizontal position of E2) can now be caused by two factors. First, a variation in the difference between the exogenous rates of growth of the knowledge stocks of two regions (as before), and, second, a difference across regions in the spillovers received from all other regions.

The latter term is largely determined by geographic location. The subset of regions to which this term refers does not differ between $i$ and $j$, but when, for example, region $i$ is closer to the advanced regions than region $j$ is, this gives region $i$ an advantage over region $j$. Also, the learning capability $\left(\delta\right.$ and $\mu$ ) has an impact on how $\left(\Sigma_{n} S_{i n}-\Sigma_{n} S_{j n}\right)$ differs between $i$ and $j$ ).

\section{Extending the model to a multi-country set-up}

The economy consists of a number of countries (denoted by $j=1 . . m$ ), each of which contains several regions (denoted by $i=1 . . n_{j}$ ). Only one good is produced (specialisation is ruled out). Demand for the good is assumed to be determined by the number of people (denoted by $N$ ), labour productivity (defined by $a=Q / L$, in which $Q$ denotes production and $L$ denotes the number people who have a job) and the world price in terms of the home currency $(e P, e$ denotes the exchange rate and $P$ the world price) for the good. Increasing labour productivity is assumed to have a positive influence on demand, since it gives an indication of a relative high general level of development of the economy. The demand function is given by the following equation:

$$
D_{i j}=\frac{d_{i j} N_{i j} a_{i j}}{e_{j} P},
$$

in which $d$ is a parameter.

Supply is assumed to be inelastic in the short run, so that it can be set equal to productive capacity $(Q)$. Capital is homogenous. Assuming a fixed coefficients production technology, 
labour demand is simply a function of the capital stock in the sector. We assume one world price for the good, which can be found by confronting world demand with world supply:

$$
\sum_{j=1}^{m} \sum_{i=1}^{n} \frac{d_{i j} N_{i j} a_{i j}}{e_{j} P}=\sum_{j=1}^{m} \sum_{i=1}^{n} l_{i j} N_{i j} a_{i j},
$$

where the share of total population employed in region $i$ of country $j$ is defined as $l_{i j}=L_{i j} / N_{i j}$ ( $L$ is labour demand, equal to $C /(a c)$, where $C$ is the capital stock, and the capital output ratio $c \equiv C / Q$ is assumed to be a fixed parameter). When (initial) levels for $C, N, a$ and $e$ are given, this equation can be solved for the world price $P$ as follows:

$$
P=\frac{\sum_{j=1}^{m} \sum_{i=1}^{n} \frac{d_{i j} N_{i j}}{e_{j}}}{\sum_{j=1}^{m} \sum_{i=1}^{n} L_{i j}} .
$$

The growth of labour productivity is assumed to be proportional to the growth of the knowledge stock:

$$
\hat{a}_{i j}=\xi \hat{K}_{i j}
$$

in which $\xi$ is a parameter which is set equal to one in the following experiments. The spillover system, as introduced in the former section, determines the knowledge stock of each region at each moment in time.

Next, we define capital accumulation. The 'real' profit rate (profits as a share of the capital stock) is defined as follows:

$$
r_{i j}=\frac{e_{j} P Q_{i j}-w_{i j} L_{i j}}{e_{j} P C_{i j}}=\frac{1}{c}\left(1-\frac{w_{i j}}{a_{i j} e_{j} P}\right),
$$

where $w$ is the nominal wage rate (measured in domestic currency). We assume that all profits are reinvested in capital in the same region, and that the price for capital equipment is equal to the world price of output. Thus, the growth rate of the capital stocks can be written as:

$$
\hat{C}=r_{i j} \text {. }
$$

Now, we add the dynamics of the exchange rates. The value of the trade balance measured in foreign currency per sector is equal to the difference between the country's production and its consumption, i.e.:

$$
B_{j}=P\left(Q_{j}-D_{j}\right) .
$$


The assumption is that the growth of the exchange rate depends on the value of the trade balance as a fraction of the value of total GDP (both measured in current prices and foreign currency). More specifically, we assume that the following equation holds:

$$
\hat{e}_{j}=\varepsilon\left(\frac{B_{j}}{P Q_{j}}-\frac{B^{*}}{P Q^{*}}\right),
$$

where $\varepsilon(>0)$ is a parameter. The superscript $*$ indicates the reference country for which the growth in the exchange rate is equal to zero, $(\hat{e}=0, e=1)$. This formulation ensures certain basic characteristics with regard to consistency. For example, a change of the reference country (i.e., expressing all values for all countries in the currency of a different country) does not change the growth rates of the exchange rates using the above equation. Also, note that the exchange rate between two countries of which neither is the reference country can be calculated by dividing their exchange rates relative to the reference country. Thus, for $m$ countries, one can calculate all remaining $\left(m^{2}-m\right) / 2$ exchange rates if the $m$ exchange rates relative to one reference country are known. The above equation for the dynamics of the exchange rate ensures that changing the reference country does not change the resulting values of the exchange rate growth rates.

The labour market is characterised by a Phillips curve, determining the growth of the nominal wage rate:

$$
\hat{w}=-m+n \frac{L_{i j}}{N_{i j}}
$$

in which $m$ and $n$ are parameters. Population $(N)$ is assumed to grow at a fixed rate $\eta$.

When we specify a (symmetric) matrix of distances between regions, the model is fully specified, and time paths for the $G$ variables result from any set of initial values. However, for more than two regions, these time paths are extremely tedious to work out analytically, which is why we resort to simulations to describe the outcomes of the model. By carrying out many simulations (with randomised initial conditions) it is possible to examine the general behaviour of the model, and we find that certain patterns in the gaps of the knowledge stocks appear repeatedly. All simulations use a Pascal computer program that implements a RungeKutta algorithm to numerically solve the differential equations for $G$.

We use two different geographical spheres (distance matrices). These are a lattice of honeycombs and a globe. Appendix A gives an exact description and a map of these spheres as well as the location of the border which divides each sphere into countries. The regions on these spheres are assumed to be homogeneous areas. In other words, no differences of the relative importance (e.g., political) of the regions are assumed, nor do we assume differences in the degree of connectedness (e.g. the presence of harbours, mountains, roads and railways). Since this is a one-sector model, we also assume that the regions have homogenous economic structures. The first of these spheres is two-dimensional. A honeycomb pattern is chosen in order to provide an equal amount of contingent neighbours for each region, with each 
neighbour having an equally long border. This would not be the case when using a lattice of squares, which would have the additional difficulty of judging the importance of the different kinds of neighbours - queens, bishops or rooks ${ }^{8}$ - by assigning weights to them. Because the lattice is flat and has a hexagonal shape in itself, there is always exactly one central region. This region has a favourable location, as will become clear from the experiments.

The second sphere used has the shape of a globe. In the globe, no inherently central location is present. In the case of the globe pentagons had to be added to the hexagons (the regions are constructed as the pattern on a soccer ball, i.e., 12 pentagons and 20 hexagons $)^{9}$. The lattice of honeycombs can be considered similar to a country, whereas the globe could be a model for a world.

Geographic distance in the geographical spheres is measured by assigning a weight of 1 to neighbouring regions (in the sense that two regions share one border). Regions which do not share a border with a specific region are given a weight by using the concept of nearest neighbours, which means that a different (lower) weight is attributed to a second order neighbour. A second order neighbour does not share a border with a specific region, but does share a border with a neighbour of the specific region. In this way, the distance $g_{i j}$ is determined for every region towards every other region. Now, it is possible to construct a region-by-region matrix of shortest paths. Then, the corresponding weights $(\gamma)$ are determined using the inverse of the orders (inverse shortest path, Hagett, Cliff and Frey, 1977). Note that this way of measuring geographical distance is a special case of $1 /\left(g_{i j}{ }^{x}\right)$ with $x$ equal to 1 .

Next, we will examine the effect of a fixed exchange rate system versus a system of flexible exchange rates. We focus on the conditions (constellations of parameters) under which fixed exchange rates compared to flexible exchange rates generate less disparity across regions. Second, the impact of barriers to knowledge spillovers is analysed by assuming that cross border knowledge flows are hampered compared to inter-country flows.

\footnotetext{
${ }^{8}$ These terms are borrowed from chess. A queen is allowed to move in all directions indicating that all 8 neighbours of a square are equally important. A lattice with these characteristics is called a Moore neighbourhood. A bishop is only allowed to move in a diagonal way, while a rook is only allowed to move horizontally or vertically, meaning that one might want to assign a different (lower) weight to a neighbours, which do not share a border but only one point (the bishops-case) than to neighbours, which do share a border (the rooks-case). When only neighbours of the rook type are considered, the plain is called a von-Neumann neighbourhood.

${ }^{9}$ It is impossible to construct a three-dimensional figure by the single use of hexagons. Hexagons will always produce a flat sphere, since the sum of the angles of three contingent hexagons is equal to 360 degrees. By adding pentagons, the total angle will be less than 360 and thus producing a three-dimensional figure. It would have been possible to construct a three-dimensional sphere by using pentagons only, however, in that case the total number of pentagons (regions) used would be twelve. The globe that is used in the simulations consists of thirty-two planes (regions), which was considered to give more interesting interactions than a sphere containing only twelve planes.
} 


\section{Flexible exchange rates versus fixed exchange rates}

In the recent literature, a discussion takes place about whether economic integration, more precisely a monetary union, will have overall positive or negative effects on the growth of the economies involved (Flam, 1992).

This section focuses on the introduction of irrevocably fixed exchange rates and the effects of this on regional growth in our mode ${ }^{10}$. Some general characteristics of the simulations will be illustrated using the globe. The geographic space of the globe is distributed between two countries in a way that each country comprises a different amount of regions. The first country contains 9 regions and is therefore labelled as small compared to the second country which consists of the resting 23 regions. Our first simulation experiment assumes that all regions are initially equal, except for their geographic location ${ }^{11}$. Figure 9 shows the coefficient of variation (the average over the last 100 periods) over the gaps in GDP per capita in all regions for fifty runs in two cases: flexible exchange rates and a monetary union.

The figure points out several things: first, the disparity under a monetary union is larger than under flexible exchange rates. This leads to the tentative conclusion that the introduction of a monetary union leads to an increase in the gaps across regions ${ }^{12}$. Second, the disparity under a monetary union shows less variability than the disparity under flexible exchange rates. A monetary union therefore leads also to a stabilisation of the outcome.

The question arises whether the monetary union will always cause a higher disparity across regions compared to the flexible exchange rate case. What influence do the parameters in the model have on the distribution of the gaps under a monetary union versus flexible exchange rates? To explore these questions we will address both geographic spaces. Simulations were generated for several start values of the parameters $\delta$ and $\rho$ and the initial level of the

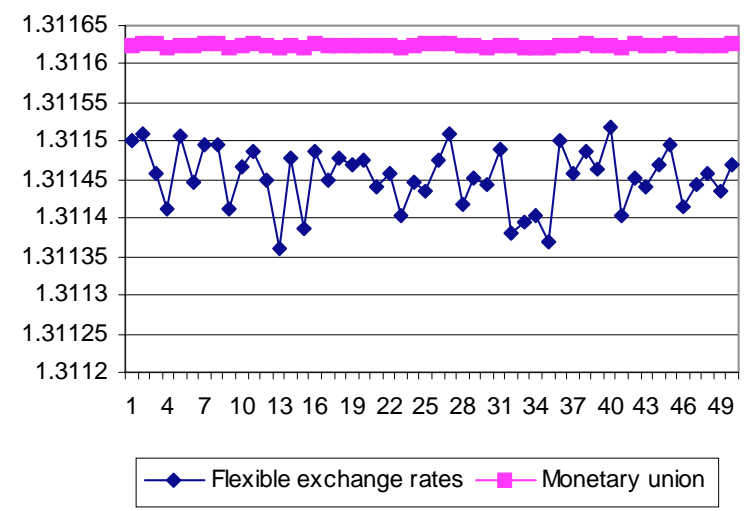

Figure 9: Overall disparity per run

\footnotetext{
${ }^{10}$ The terms 'monetary union' and 'system of fixed exchange rates' will be used interchangeably, since in terms of the model a system of fixed exchange rates is identical to a monetary union. Both refer to a situation in which each currency can be denominated in the currency of another country against a fixed rate.

${ }^{11}$ The initial values of the data are described in Appendix B. Note that the population varies across runs, but not across regions.

${ }^{12}$ The difference in the disparity between flexible exchange rates and a monetary union is quite small in absolute terms, however, a clear difference is present. Note that the coefficient of variation over the gaps in the labour productivity is taken, where the gap is defined by a logarithmic function, which suppresses high values.
} 
knowledge stock. At the start of each simulation all regions had exactly the same 'endowments', in the sense that each region has an equal learning capability, level of the knowledge stock, population etc. (Appendix B shows the initial values of all parameters and variables). Across simulations, the parameters and variables were initially set at a different level. In each constellation, the coefficient of variation was determined in the case of flexible exchange rates and a monetary union. Figure 10 gives a visual impression of the results for the lattice of honeycombs. On the horizontal axis the value of the learning capability, which varied from 0.5 to 4.5 is denoted. The vertical axis shows the exogenous rate of growth of the knowledge stock that varied in the same interval. A grey cell indicates that the disparity under a monetary union was higher than under flexible exchange rates. The five different panels are made for five different values of the initial level of the knowledge stock.

Figure 10: Differences in disparity between a monetary union and a system of flexible exchange rates: results for the lattice of honeycombs

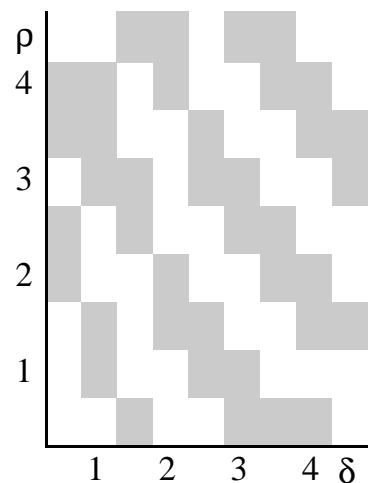

Knowledge stock $=$ 0.5

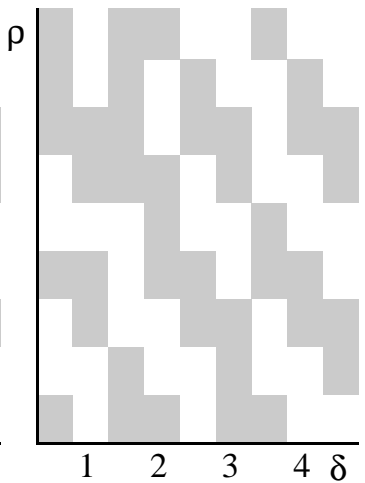

Knowledge stock $=$ 2.5

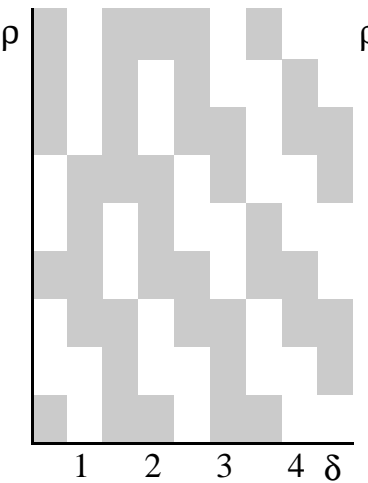

Knowledge stock $=$ 4.5

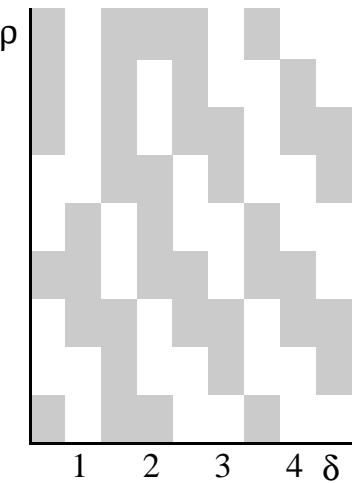

Knowledge stock $=$ 6.5

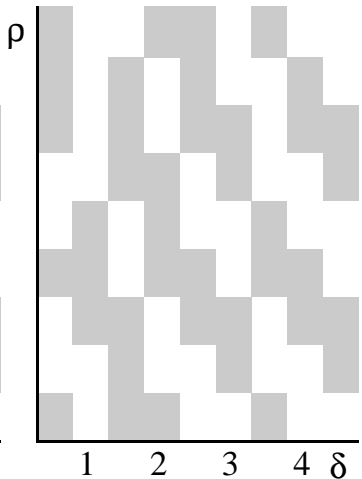

Knowledge stock $=$ 8.5

Several interesting phenomena are illustrated by this figure. First, a clear pattern is shown in the panels. There appear to be zones, which stretch from the upper left to the lower right. In each zone, either a monetary union or a system of flexible exchange rates causes more disparity across regions. The combination of learning capability and exogenous rate of growth of the knowledge stock therefore causes the disparity in the monetary union to be higher or lower than under flexible exchange rates. Second, as the knowledge stock is increased, some changes occur in the pattern, but these appear to be less systematic. This indicates that a change in the initial level of the knowledge stock has only little influence on whether a monetary union causes more disparity across regions than flexible exchange rates.

Furthermore, Figure 10 shows several cells that do not change colour as the knowledge stock is increased. In general, it is the case that if the knowledge stock has reached a relatively high value (8.5), the cells will not change colour anymore due to a further increase in the initial level of the knowledge stock. The situation is now stable in that either the monetary union or the flexible exchange rates case shows the largest disparity.

This overall result emphasises that under certain combinations of the learning capability and the exogenous rate of knowledge generation more disparity might occur as a result of the 
introduction of a monetary union. This contradicts the general believe that the introduction of a monetary union will generate convergence across the participation countries/regions.

More precisely, the results indicate that both parameters (the learning capability, $\delta$, and the exogenous rate of growth of the knowledge stock, $\rho$ ) and a variable (the level of the knowledge stock at the start of the simulation) all have an influence on whether a monetary union induces a lower or higher disparity across regions than flexible exchange rates. The influence of initial level of the knowledge stock becomes marginal as it reaches a high value. However, the influence of $\delta$ and $\rho$ is much higher. An enlargement of the learning capability (keeping $\rho$ and the initial level of the knowledge stock equal) will lead to several switches in colour in Figure 10. This indicates that a small change in the learning capability induces a new situation in which either a monetary union or flexible exchange rates cause the highest disparity across regions. The exogenous rate of growth of the knowledge stock has a less strong impact. As $\rho$ is increased (all other things equal) there appear large intervals in which a monetary union generates a larger disparity across regions than flexible exchange rates and the other way around. This might lead to the conclusion that it is easier to use the exogenous rate of growth of the knowledge stock as a policy instrument (for example by increasing the amount of R\&D) than influencing the learning capability of all regions. Influencing the learning capability might lead to overshooting of the objective that the introduction of a monetary union leads to less disparity than would be the case as flexible exchange rates were maintained.

Figure 11 shows the results for the globe. A clear division appears between the grey and the white areas. As the knowledge stock is enlarged, the grey area becomes larger. Thus, we find more constellations in which the disparity caused by a monetary union is larger than the disparity under flexible exchange rates. We see that from the point that the knowledge stock is equal to 4.5 a grey area emerges at the left-hand side of the panel, reducing the white area from left to right.

This figure points out that as the initial level of the knowledge stock is increased across regions, the grey area is enlarged, until finally the parameters no longer have an influence on the direction of the difference. At high values of the knowledge stock, each combination of $\delta$ and $\rho$ leads to a situation in which a monetary union causes a larger disparity than a system of flexible exchange rates. Applying the globe as the prevailing geographic structure we find that in many cases (parameter constellations) a monetary union leads to divergence in regional growth. This is a remarkable result, considering the implicit assumption of the European Union that integration favours convergence in growth across regions. 
Figure 11: Differences in disparity between a monetary union and a system of flexible exchange rates: results for the globe

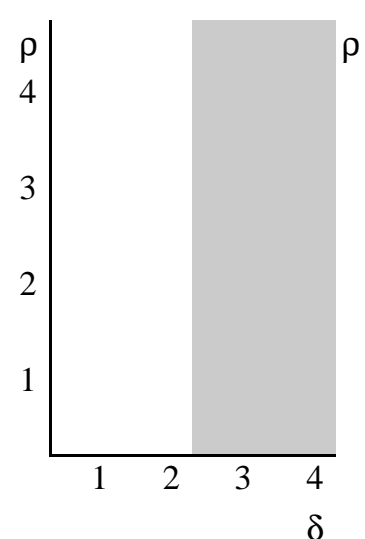

Knowledge stock $=$ 0.5

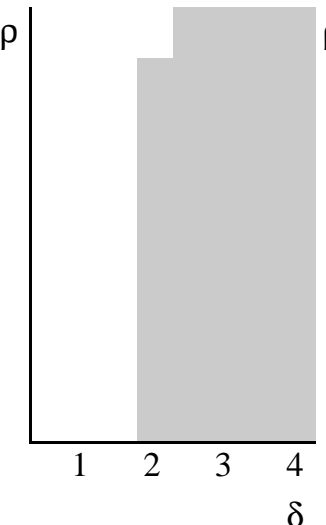

Knowledge stock $=$ 3

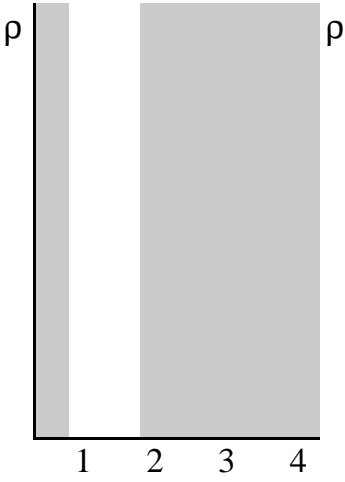

$\delta$

Knowledge stock $=$ 4.5

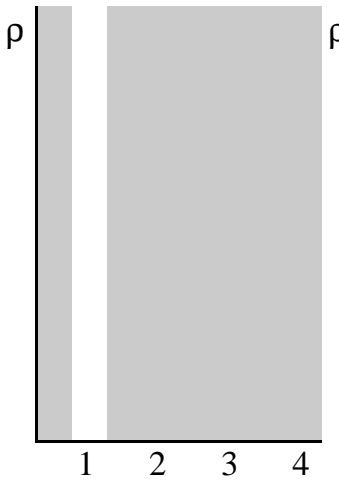

$\delta$

Knowledge stock $=$ 5.5

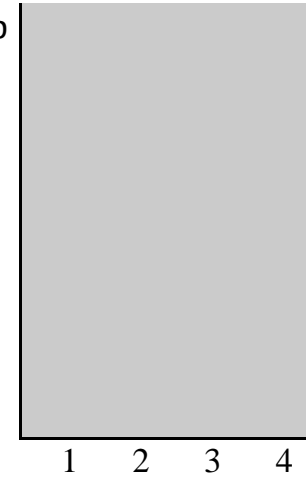

$\delta$

Knowledge stock $=$ 7

This section illustrated what effects different conditions (constellations of parameters like the learning capability and the exogenous rate of growth of the knowledge stock) have on the disparity in the gaps of the knowledge stock across regions. These conditions are explored in two different stages of integration, namely a system of flexible exchange rates and a monetary union. The choice of the geographical sphere has a large impact on the results. The lattice of honeycombs might be the most realistic sphere to compare with the European Union. In this sphere, we see that specific combinations of the learning capability and the exogenous rate of growth of the knowledge stock lead to less disparity across regions in the case of a monetary union, but other combinations show an adverse effect. This leads to the conclusion that a monetary union does not unambiguously lead to convergence in regional gaps.

\section{Barriers to knowledge spillovers}

The existence of national systems of innovation stimulates inter-country regional interaction rather than cross border relationships. The experiments in this section aim to explore the effect of barriers to knowledge spillovers on regional convergence. In this section, a barrier to knowledge spillovers across countries is introduced by reducing the spillovers that cross the border between the countries with one half. The specific effect of introducing knowledge barriers to this model is analysed by comparing the results of this experiment to the results found for the situation of no barriers to knowledge spillovers. This is documented in Figures 14 and 17. The underlying geographical structure is the lattice of honeycombs.

In this experiment, the initial level of the knowledge stock for each region is drawn from a uniform distribution, resulting in several different initial distributions of the knowledge stock across regions. These initial disparities are displayed on the horizontal axis of the figures. The vertical axis shows the coefficient of variation at the end of the simulation period. Several things emerge from comparing Figure 12 to Figure 13. 


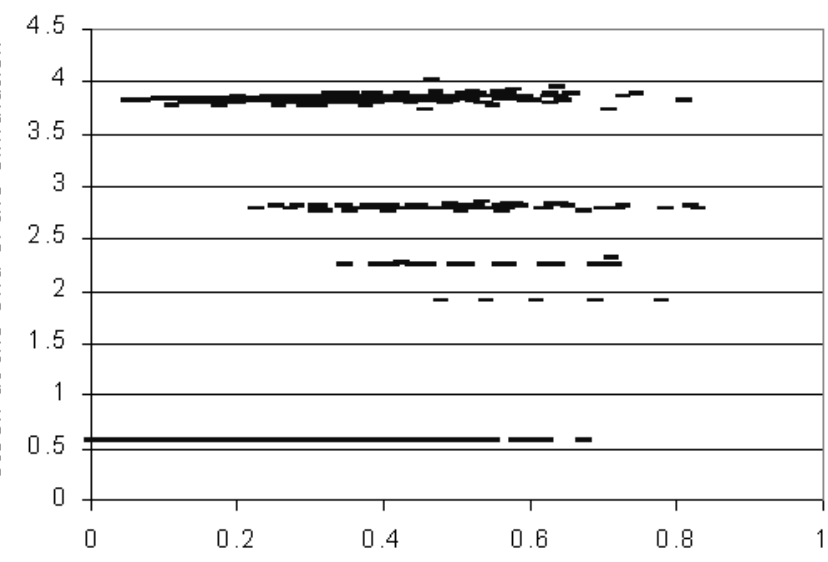

Coefficient of variation of the knowledge stock at the start of the simulation

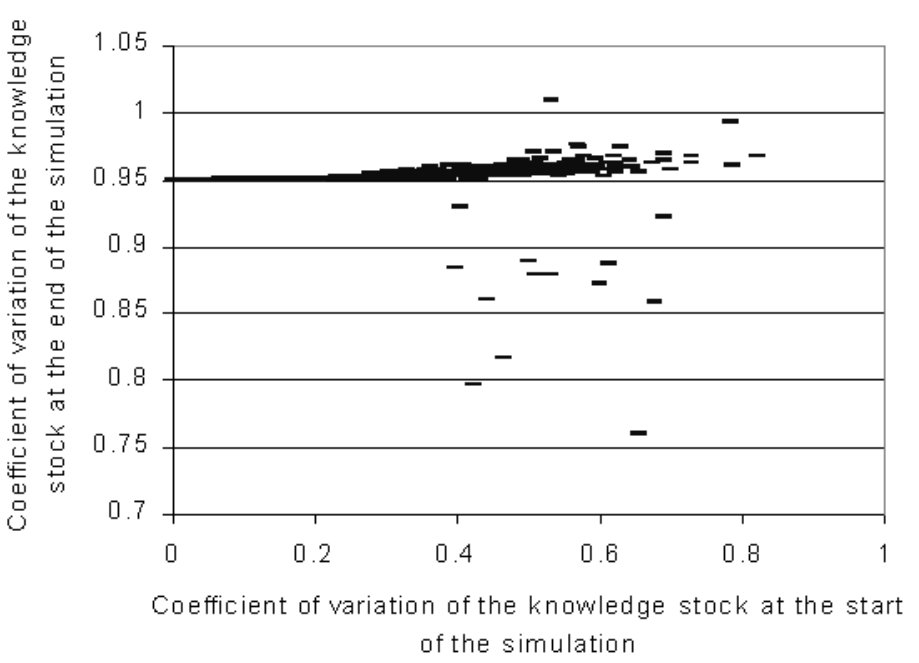

Figure 13: Barriers to knowledge spillovers

Figure 12: No barriers to knowledge spillovers

In brief, the case in which there are no barriers to knowledge spillovers shows a prominent presence of falling behind. In fact, only the case in which the final coefficient of variation is about 0.6 indicates a situation in which no regions fall behind. The accompanying distribution of the gaps across regions in displayed in Figure 14. Note that a certain polarisation occurs, meaning that the regions that are geographically close to the central region display the lowest gaps.

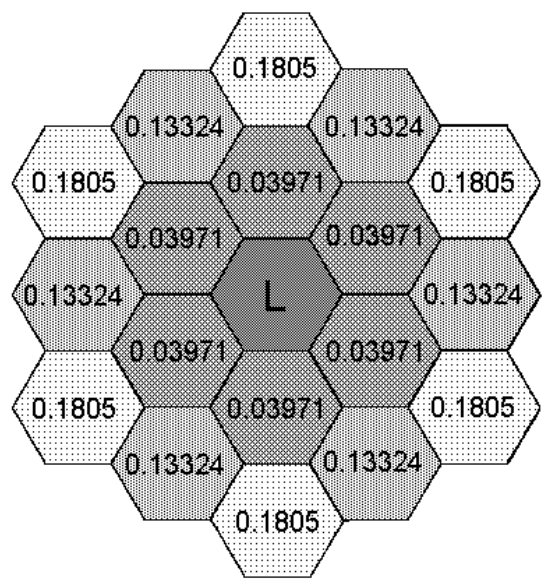

Figure 14: Regional gaps in a lattice of honeycombs

Turning to Figure 13 for the introduction of barriers to knowledge spillovers in the experiment, we find many observations with a coefficient of variation ranging from nearly 0.95 up to almost 0.98 at the right-hand side of the figure. The broadness of the range indicates that many runs have a similar, however slightly different, coefficient of variation. The differences in disparity within this small range are due to the 'normal' variation between runs within one interval.

The figure displays a few observations with a coefficient of variation of about 0.875 . This is the effect of falling behind of regions within the second country (the leader). Falling behind in this experiment is much less compared to the strong presence in the case of no barriers to 
knowledge spillovers. Falling behind in Figure 13 leads to less final disparity, contrary to the case of no barriers to knowledge spillovers in which falling behind induced a higher disparity at the end of the simulation. When knowledge spillovers across countries are hampered all regions within the first country will experience a large gap towards the leader region, which is located in the second country (this will be explored more in detail in Figure 16). When a region from within country 2 experiences falling behind (due to unfavourable low initial values of its knowledge stock), this induces the overall disparity to decline. Since only a small number of runs is subject to falling behind, we can conclude that under barriers to knowledge spillovers, falling behind has less of an impact on the disparity than before.

Another point originates from Figure 13. At the right-hand side, the coefficient of variation is slightly higher than to the left, while this effect is absent from Figure 12. Because the first country receives little spillovers due to the barriers to cross border spillovers, the equilibrium gap (towards every individual region from this country converges) continues to grow during the transitory dynamics. At a high initial coefficient of variation (right-hand side of the figure), large initial differences between regions are present. Apparently, this causes a relatively high variety in equilibrium gaps across regions (of the first country) within a run. Therefore, the overall disparity is higher than in the case where initial differences across regions are smaller (left-hand side of the figure).

The two panels in Figure 15 show the effect of barriers to knowledge spillovers as there are initial variations in the learning capability and the exogenous rate of growth of the knowledge stock, respectively. Both parameters are drawn from a uniform distribution of decreasing size, where the upper boundary is fixed, and the lower boundary is shifted. The horizontal axis in each panel in Figure 15 shows the lower boundary. The upper boundary was set equal to 2 throughout the simulations ${ }^{13}$. The vertical axis shows the frequency of the coefficient of variation of the gaps. The shades in the figures correspond to frequencies over 50 runs, with

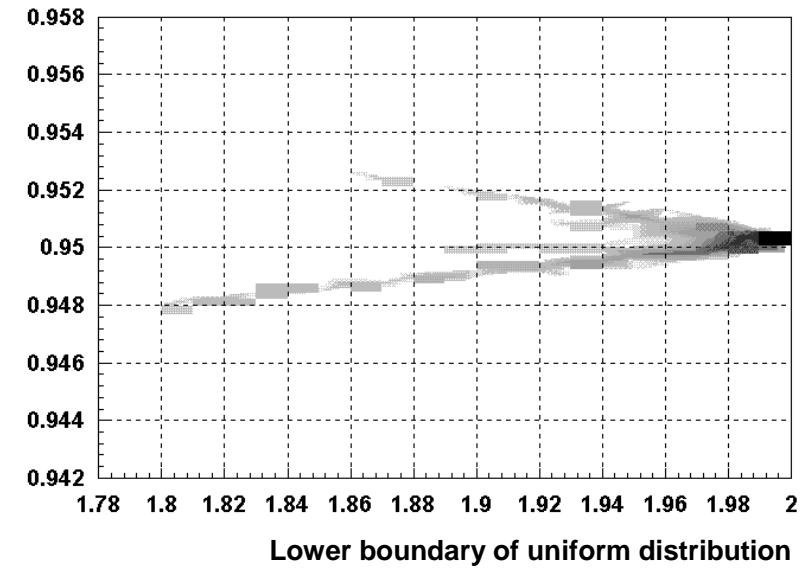

Figure 15, Panel 1: Frequency diagram of the coefficient of variation at the end of the run. Initial variation in the learning capability

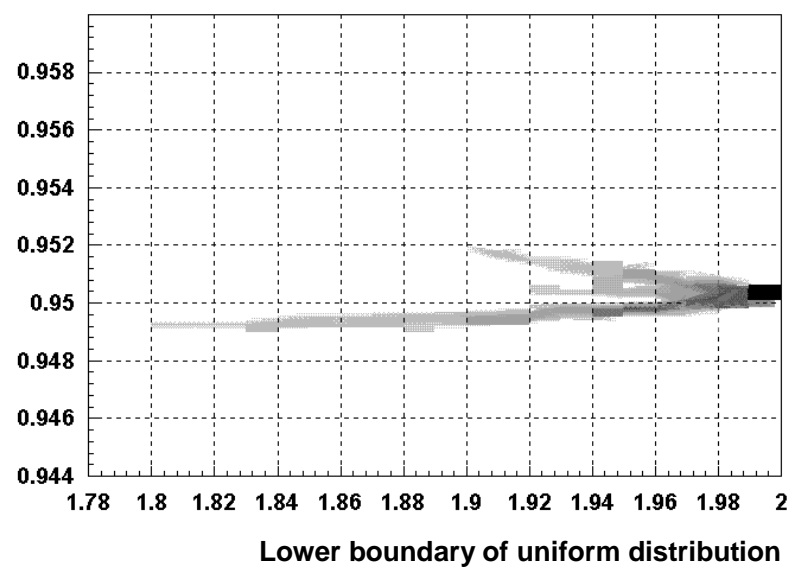

Figure 15, Panel 2: Frequency diagram of the coefficient of variation at the end of the run. Initial variation in the exogenous rate of knowledge generation

\footnotetext{
${ }^{13}$ Appendix B shows the values of all parameters and variables as they are used for each (set of) simulations.
} 
complete black corresponding to a frequency of 50 (i.e., all runs). White shades indicate very low (sometimes zero) frequencies.

The first panel of Figure 15 shows the results for an initial variation in the learning capability. A comet-shape appears, in which 'the comet' (the dark spot at the right of the figure) leaves two clear trails: a long one coming from the lower left and a shorter trail originating from the upper left. This indicates that an increase in initial disparity across regions induces two effects. The upper trail suggests higher disparity, however, a stronger effect originates from the lower trail, which suggests smaller disparity across regions. The more unequal regions are in terms of their learning capability, the more differences in disparity exist across runs.

A similar comet-shape appears when we observe the results for a variation in the exogenous rate of growth of the knowledge stock (Figure 15, Panel 2). Again, there appear two trails of which the lower one is longer. Based on this observation, a variation in the exogenous rate of growth of the knowledge stock seems to have a similar influence on the behaviour of the model than a variation in the learning capability (although the absolute influence differs).

It is interesting to observe the distribution of the gaps (after 1000 simulation periods) across regions in the case that all regions are initially equal, except for their geographic location (see Figure 16). Thus, $\delta_{\mathrm{i}}=\delta, \mu_{\mathrm{i}}=\mu$, and initially all values for $G$ are equal to zero. The values for the parameters $\delta$ and $\mu$ remain fixed over the run, while the values for $G$, naturally, evolve according to equation (5'). The number within each honeycomb in Figure 16

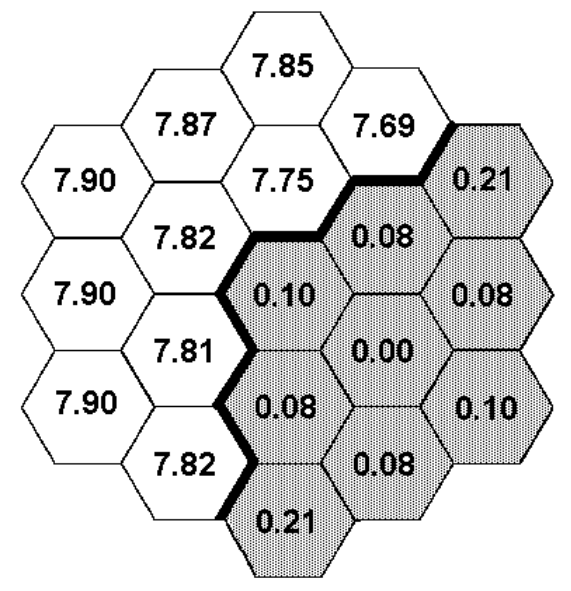

Figure 16: Final gaps when all regions

are initially equal

indicates the size of the gap of the region toward the leader region ${ }^{14}$. The regions that have a large gap towards the leader region are white whereas the leader region and regions with a very small gap towards the leader are coloured grey. The thick line demarcates the border between the two countries.

\footnotetext{
${ }^{14}$ Note that these are average values over the last 100 periods in a run.
} 
The pattern shows strong inter-country variation, rather than inter-regional variation. All regions within a country have identical colours. The origins for this pattern are found in the first periods of the run. The second country comprises the region that on a world level has the most favourable geographic location, the central region. This simple fact causes that country 2 in the end becomes the leader country. The centrally located region (in the world) will receive most spillovers in the first periods of the run, only because of its central position. At the same time the regions of country 1, neighbouring to this central region, undergo a large disadvantage of the border. Their spillovers from the advanced country 2 are reduced by one half. This process is reinforced as the simulation time passes.

A second observation is that in the second country the leader region is located in the most favourable geographic position (the central location) within the country. The world-leader region is therefore not the 'overall' central region in world. The other regions within country 2 show gaps which are (line-) symmetrically distributed around the leader region. Thus, within country 2 the 'usual' polarisation (as documented in Figure 14) takes place, in the sense that the regions that are geographically close to the central region display the lowest gaps.

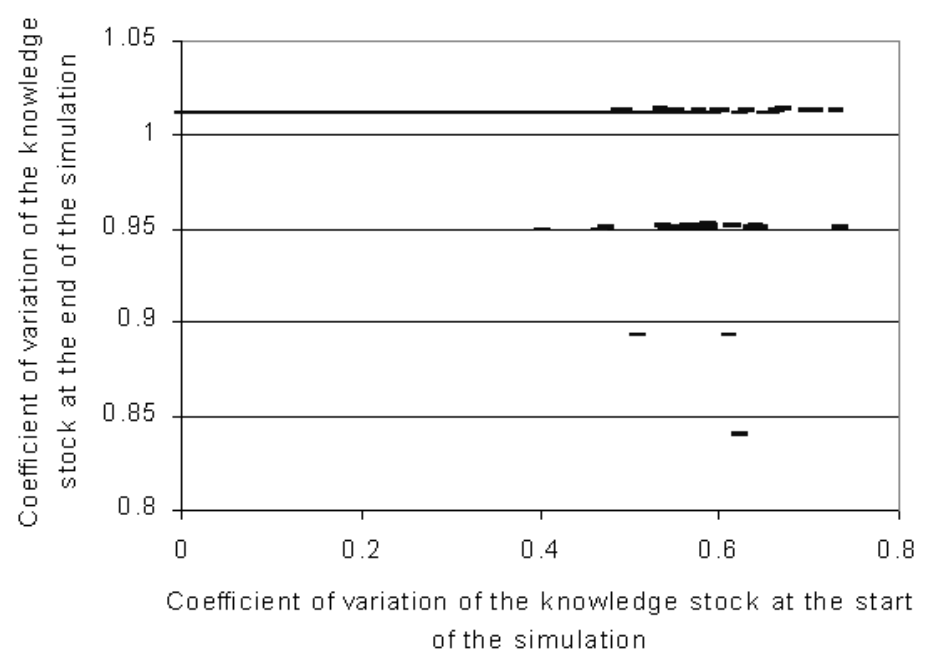

Figure 17: Initial versus final disparity under barriers to knowledge spillovers, the globe

Summarising, a variation in one of the parameters (learning capability or exogenous rate of growth of the knowledge stock) suggests that two states appear most often as the initial differences across regions increase with respect to one of the two parameters. In one state the disparity is larger than in the distribution shown by Figure 16, in the other state the disparity in the gaps across regions is smaller. The latter trail is clearest suggesting that initial differences in learning capability or exogenous rate of knowledge generation leads to a lower disparity across regions.

The sphere used in the last set of simulations is the globe. A variation in the initial stock of knowledge across regions leads to a disparity in gaps across regions as displayed in Figure 17. Whereas the final disparity of 1.0117 results independent of the initial disparity across regions, a few times a lower final coefficient of variation comes about. Similar to the 
experiment for the lattice of honeycombs this is due to falling behind within the leader country.

Panel 1 of Figure 18 shows the disparity in each run for a variation in the learning capability. A comet-shape occurs, indicating that an increase in initial disparity across regions induces not only less disparity across regions at the end of the simulation but could also cause more disparity. The more unequal regions are in terms of their exogenous rate of growth of the knowledge stock, the more differences in disparity exist across runs. However, there seem to be (three) different paths along which the coefficient of variation groups (three trails). One trail is moving upward from the black cell towards the upper left. A second path stretches out in a slightly downward direction (from right to left). The third trail is horizontal. Panel 2 shows the results for a variation in the learning capability. Again, a comet-shape appears, however, no separate trails are distinguished.

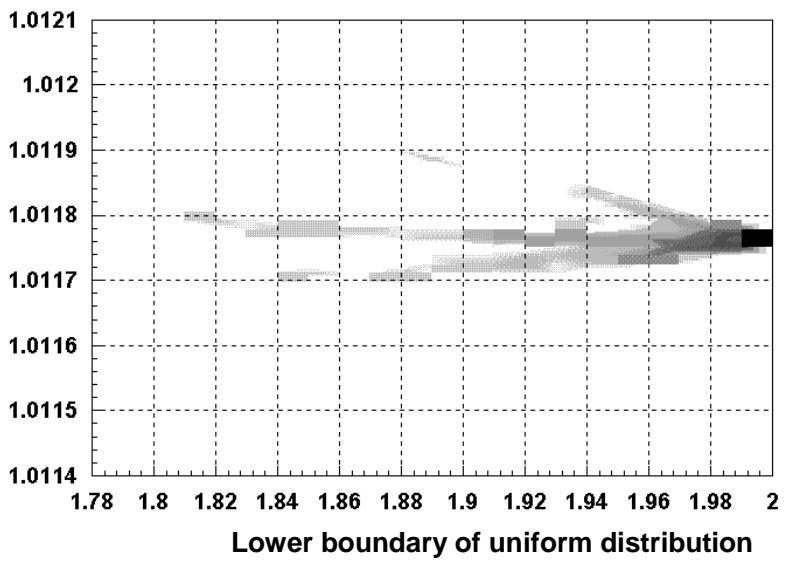

Figure 18, Panel 1: Frequency diagram of the coefficient of variation at the end of the run

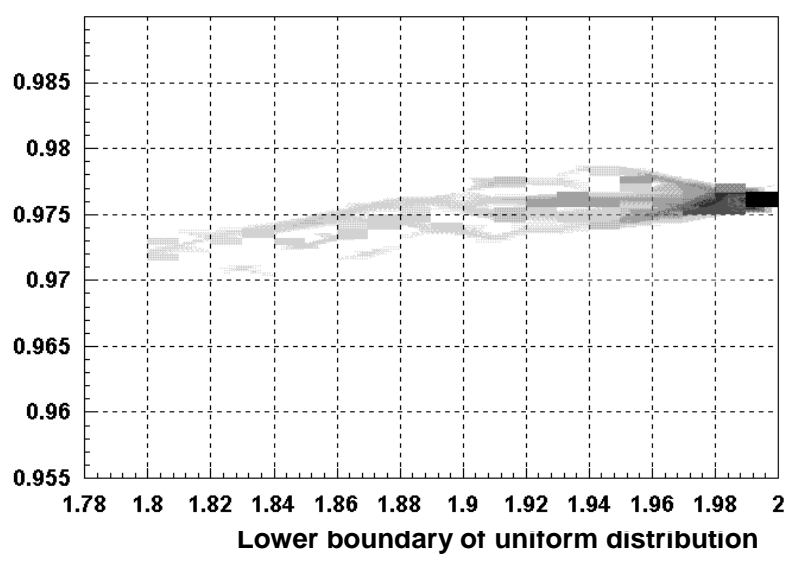

Figure 18, Panel 2: Frequency diagram of the coefficient of variation at the end of the run

In general, the figures for this geographical sphere show similar trends as for the lattice, although the amount, direction and clarity of the trails (for an initial random variation in $\delta$ or $\rho)$ differs somewhat.

The distribution connected to the situation in which regions have the same initial values is shown by Figure $19^{15,16}$. As before we find a strong inter-country difference. Within the leader country a polarisation occurs (less clear from Figure 19) around the leader region.

This set of experiments sheds light on the effect of barriers to knowledge spillovers on the model. A striking result is that a clear difference in the average gap between two countries occurs. In one country, all regions will tend to an equilibrium in which their gap toward the

\footnotetext{
${ }^{15}$ It might strike as remarkable that Panel 2 shows a lower final coefficient of variation than in Panel 1. This is due to the fact that learning capability is set equal to 2 in this experiment, while it was set equal to 1 in the first set of simulations (see Appendix B).

${ }^{16}$ Note that the geographic structure of country 2 is a-symmetrical. Therefore, it is less easy to see that the leader region is centrally located within country 2 . The same experiment has been executed for a different, symmetric geographic structure for both countries. The results with respect to disparity (for all ranges) are similar. The only advantage of a symmetric geographic structure is that it enables us to immediately see the polarisation around the central region of the leader country.
} 
leader region (located in the other country) is very large. The country containing the leader region shows polarisation. This result indicates that the 'adverse' effect of variety in learning capability and exogenous rate of growth of the knowledge stock, i.e. more initial variety causing less final disparity across regions, only holds within a country.

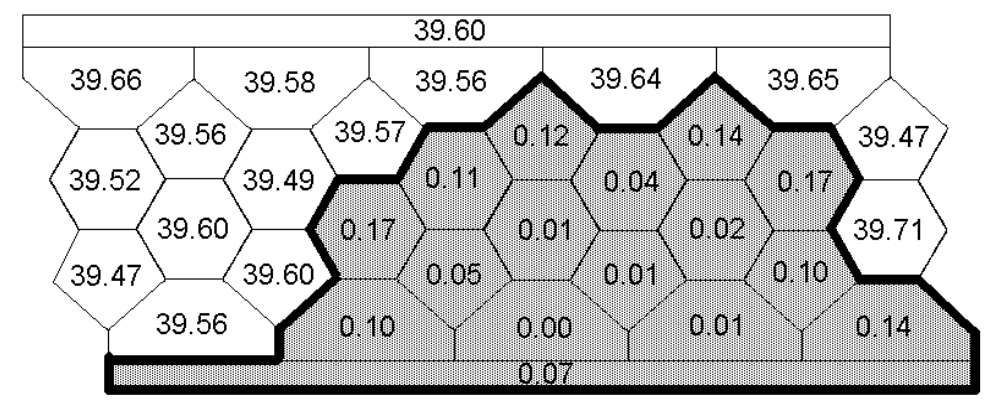

Figure 19: Final gaps when all regions are initially equal

\section{Summary and conclusions}

This paper presented a model for knowledge spillovers based on geographical distance as well as technological distance. The regions in our model receive knowledge spillovers from other regions, and this enables them to grow rapidly. Our model is similar to some of the models found in the 'technology gap' tradition of analysing convergence of GDP per capita. Compared to these models, we add the spatial distance effect on spillovers. The further away other regions are, the less strong spillovers from these regions are.

In addition, this paper developed a multi-country model, in which inter-regional knowledge spillovers determine the growth of regions. By simulations we examined the effect of parameters such as the learning capability and the exogenous rate of growth of the knowledge stock on disparity in different situations. First, the effect of barriers to trade was investigated by comparing two different stages of integration. A fixed exchange rate system versus a system of flexible exchange rates was examined, resulting in conditions (constellations of parameters) under which fixed exchange rates (compared to flexible exchange rates) generate less disparity across regions. However, depending on the parameter values, fixed exchange rates may also generate more disparity, leading to the conclusion that the effect of monetary integration is ambiguous.

Second, attention was paid to barriers to knowledge spillovers in the sense that cross border knowledge flows are hampered compared to inter-country flows. This experiment leads to the result that reduced cross border flows have a large implication when regions are initially unequal with respect to their knowledge stocks, the exogenous rate of knowledge generation or the learning capability. The most important result from this last experiment is that a difference between countries appears in the resulting pattern of per capita gaps. One of the two countries contains the leader region and this region is located centrally within this country. All other regions of the leader country are grouped in a hierarchical pattern around the central region. The other country contains regions that have a large gap towards the world leader region. This indicates that, with limited cross-border spillovers, the 'adverse' effect of 
variety in learning capability and exogenous rate of growth of the knowledge stock, i.e., more initial disparity resulting in less final disparity, only holds within a country.

\section{APPENDIX A}

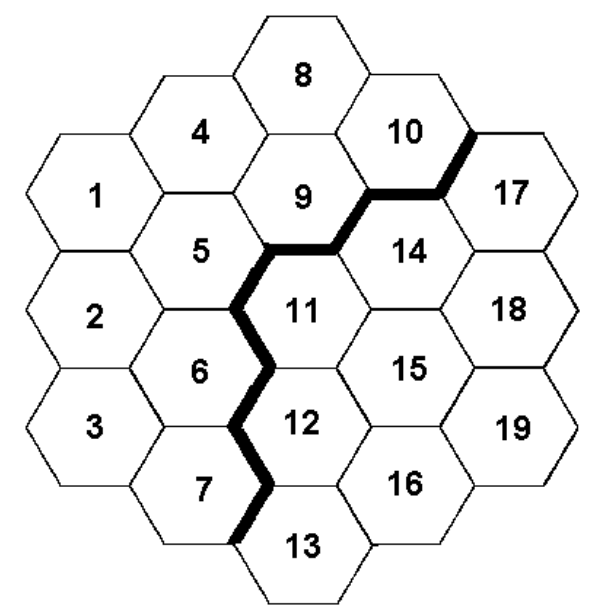

Figure A.1: Two countries on a lattice of honeycombs

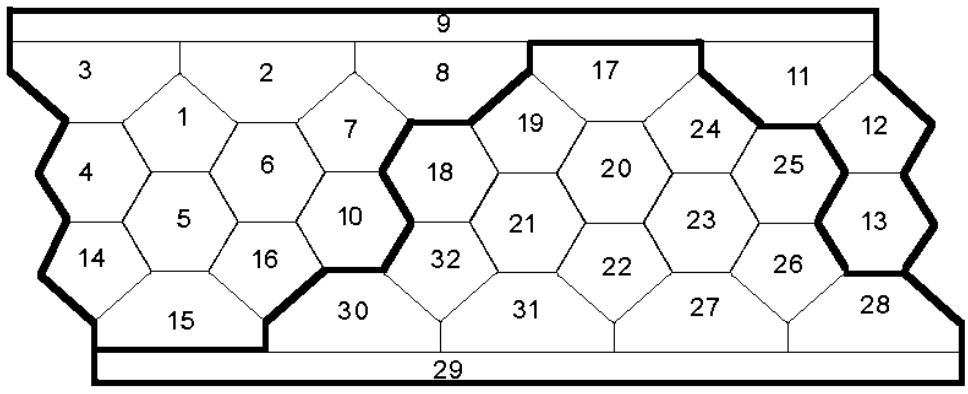

Figure A.2: Two countries on a globe

Figure A.1 displays the topography of the regions on a lattice of honeycombs. The number within each hexagon was used to establish the geographical distances between all hexagons. Figure A.2 represents a globe with 12 pentagons and 20 hexagons. For the graphical representation, we used the same principle that was applied in making a map of the world. Hence, the regions close to the poles look larger as they actually are, while the regions around the equator show their true proportions. At the bottom and at the top are regions 29 and 9 . These are pentagons, for example region 9 borders to five regions, namely 3, 2, 8, 10 and 11. Regions 29 and 9 are in reality as large as region 1 . The graphic representation of a globe has also as a consequence that for example region 3 seems to differ in size from region 6. Again, this is not the case in reality, region 3 is an ordinary hexagon. The same goes for all the other regions bordering 9 or 29. It should also be noted that region 11 borders not only to regions $9,10,24,25$ and 12, but also to region 3. In this way, region 12 also borders to regions 3 and 4, region 13 has regions 4 and 14 as direct neighbours as well, whereas region 28 also shares a border with regions 14 and 15 . 


\section{APPENDIX B}

Default levels of the variables and values of the parameters:

$\begin{array}{ll}1 & (\text { Catch-up parameter, } \mu) \\ 0.005 & (\beta) \\ 0.005 & (\alpha) \\ 1 & (\text { Verdoorn parameter, } \lambda) \\ 1 & (\zeta) \\ 0.01 & (\varepsilon) \\ 0.008 & (\eta) \\ 3 & (c) \\ 1 & (d) \\ 0.8 & (m) \\ 1 & (n)\end{array}$

Exchange rate country $1=1.14$, (exchange rate country $2=1$ )

$\gamma$ (geographical distance) is constructed with the help of two different types of distance tables, one for each sphere.

Level of the knowledge stock and values of the parameters in each figure:

\begin{tabular}{|c|c|c|c|c|c|c|c|c|c|c|c|c|c|c|}
\hline $\begin{array}{l}\text { II } \\
\text { a }\end{array}$ & $\begin{array}{l}\text { N } \\
\text { II } \\
\text { Q }\end{array}$ & $\begin{array}{l}\text { N } \\
\text { II } \\
0\end{array}$ & II & $\begin{array}{l}+ \\
\text { II } \\
\text { D }\end{array}$ & 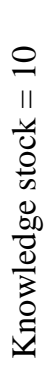 & 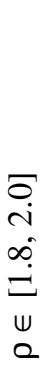 & 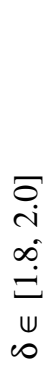 & 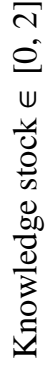 & 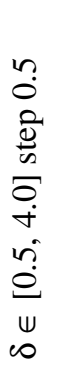 & 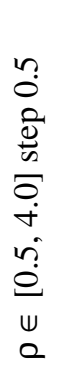 & $\begin{array}{l}n \\
0 \\
0 \\
\tilde{D} \\
\tilde{n} \\
\tilde{n} \\
\tilde{+} \\
\tilde{o} \\
\tilde{0} \\
w \\
\infty\end{array}$ & 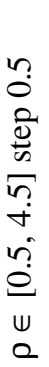 & 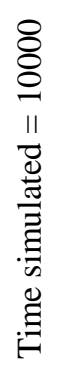 & 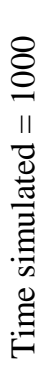 \\
\hline & $\mathrm{X}$ & & & $\mathrm{X}$ & $\mathrm{X}$ & & & & & & & & & $\mathrm{X}$ \\
\hline & & & & & & & & & $\mathrm{X}$ & & $\mathrm{X}$ & & & $\mathrm{X}$ \\
\hline & & & & & & & & & & $\mathrm{X}$ & & $\mathrm{X}$ & & $X$ \\
\hline $\mathrm{X}$ & & & $\mathrm{X}$ & & & & & $\mathrm{X}$ & & & & & $\mathrm{X}$ & \\
\hline $\mathrm{X}$ & & & $\mathrm{X}$ & & & & & X & & & & & & $\mathrm{X}$ \\
\hline $\mathrm{X}$ & & & $\mathrm{X}$ & & $\mathrm{X}$ & & & & & & & & $X$ & \\
\hline $\mathrm{X}$ & & & & & $\mathrm{X}$ & & $\mathrm{X}$ & & & & & & & $\mathrm{X}$ \\
\hline & & & $X$ & & $\mathrm{X}$ & $\mathrm{X}$ & & & & & & & & $\mathrm{X}$ \\
\hline $\mathrm{X}$ & & & $X$ & & $\mathrm{X}$ & & & & & & & & & $\mathrm{X}$ \\
\hline $\mathrm{X}$ & & & $X$ & & & & & X & & & & & & $\mathrm{X}$ \\
\hline & & $\mathrm{X}$ & & & $\mathrm{X}$ & & $\mathrm{X}$ & & & & & & & $\mathrm{X}$ \\
\hline & & & $\mathrm{X}$ & & $\mathrm{X}$ & $\mathrm{X}$ & & & & & & & & $X$ \\
\hline $\mathbf{X}$ & & & 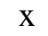 & & X & & & & & & & & & $\mathrm{X}$ \\
\hline
\end{tabular}




\section{References}

Abramovitz, M.A., (1994), 'The Origins of the Postwar Catch-Up and Convergence Boom', in: Fagerberg, J., Verspagen, B. and N. Von Tunzelmann (eds), The Dynamics of Trade, Technology and Growth, Aldershot: Edward Elgar, pp. 21-52.

Acs, Z.J., Audretsch D.B. and M.P. Feldman, (1992), 'Real effects of academic research: comment', American Economic Review, vol. 82(1), pp. 363-367.

Audretsch D.B. and M.P. Feldman, (1996), 'Knowledge spillovers and the geography of innovation and production', American Economic Review, vol. 86(3), pp. 630-640.

Baptista, R., (1998), 'Clusters, innovation and growth: a survey of the literature', in Swann, P.G.M., (ed.), The dynamics of industrial clustering - international comparisons in computing and biotechnology, Oxford: Oxford University Press, pp. 13-51.

Barro, R.J. and X. Sala-i-Martin, (1991), 'Convergence across states and regions', Brooking Papers Economic Activity, vol. 1, pp. 107-182.

Barro, R.J. and X. Sala-i-Martin, (1992a), 'Convergence', Journal of Political Economy, vol. 100, pp. 223-251.

Barro, R.J. and X. Sala-i-Martin, (1992b), 'Regional growth and migration: A Japan-United States comparison', Journal of the Japanese and International Economies, vol. 6, pp. 312346.

Barro, R.J. and X. Sala-i-Martin, (1995), Economic growth, New York: McGraw-Hill.

Barro, R.J., (1984), Macroeconomics, New York: Wiley.

Baumol, W., (1986), 'Productivity growth, convergence and welfare: What the long-run data show', American Economic Review, vol.76, pp. 1072-1085.

Ben-David, D., (1994), 'Income Disparity among Countries and the Effects of Freer Trade', in: Pasinetti, L.L. and R.M. Solow, Economic Growth and the Structure of Long-Term Development, London: St. Martin's Press, pp. 45-64.

Breschi, S., (1995), 'Spatial patterns of innovation: evidence from patent data', paper presented at the workshop on 'New Research Findings: The Economics of Scientific and Technological Research in Europe', Urbino, Italy, 24-25 February 1995.

Caniëls, M.C.J., (1999), Regional Growth Differentials, the Impact of Locally Bounded Knowledge Spillovers, Maastricht: Datawyse.

De Long, J.B., (1988), 'Productivity growth, convergence and welfare: comment', American Economic Review, vol.78, pp. 1138-1159.

Fagerberg, J., (1994), 'Technology and international differences in growth rates', Journal of Economic Literature, 32, pp. 1147-1175.

Fagerberg, J., Verspagen, B., Caniëls, M.C.J., (1997), 'Technology, Growth and Unemployment across European Regions', Regional Studies, 31, pp. 457-466.

Flam, H., (1992), 'Product markets and 1992: full integration, large gains', Journal of Economic Perspectives, vol. 6, pp. 7-31.

Freeman, C., (1991), 'Networks of innovators: a synthesis of research issues', Research Policy, vol. 20, pp. 499-514.

Grossman, G. and E. Helpman, (1990), 'Trade, innovation and growth', American Economic Review, vol. 80(2), pp. 86-92. 
Hagett, P., A. D. Cliff and A. Frey, (1977), Locational models, London: Edward Arnold (publishers) Ltd.

Jaffe, A., (1989), 'Real effects of academic research', American Economic Review, vol. 79, pp. 957-970.

Jaffe, A., Trajtenberg, M. and R. Henderson, (1993), 'Geographic localization of knowledge spillovers as evidenced by patent citations', Quarterly Journal of Economics, vol. 108, pp. 577-598.

Malerba, F., and L. Orsenigo, (1995), 'Schumpeterian patterns of innovation', Cambridge Journal of Economics, vol. 19(1), pp. 47-66.

Pavitt, K. (1987), On the nature of technology, Brighton: University of Sussex - Science Policy Research Unit.

Verspagen, B., (1991), 'A new empirical approach to catching up and falling behind', Structural Change and Economic Dynamics, vol. 2, pp. 359-380.

Von Hippel, E., (1988), The sources of innovation, New York: Oxford University Press.

Von Hippel, E., (1994), "Sticky information" and the locus of problem solving: implications for innovation', Management Science, vol. 40(3), pp. 429-439. 